International Journal of Social Science And Human Research

ISSN(print): 2644-0679, ISSN(online): 2644-0695

Volume 04 Issue 12 December 2021

DOI: 10.47191/ijsshr/v4-i12-40, Impact factor-5.586

Page No: $3747-3755$

\title{
Phase Transitions and Bifurcation Points in the Initiation Dynamics of Venture Emergence: A Conceptual Framework
}

\author{
N. S Akilu ${ }^{1}$, Fodio Garba ${ }^{2}$ \\ ${ }^{1}$ Department of Business Administration Usmanu Danfodiyo University, Sokoto \\ ${ }^{2}$ Department of public Administration Usmanu Danfodiyo University, Sokoto
}

\begin{abstract}
Based on isomorphic considerations, this paper attempts to establish an entrepreneur as complex adaptive system, which is one of the concepts that appear prominently in the field of complexity sciences. The attempt to equate the notion of an entrepreneur with the idea of a complex adaptive system, presupposes recognition of the entrepreneur's role in adaptive agency. Along with this recognition, comes the convenience of contextualizing the concepts of phase transitions and bifurcation points in terms of venture emergence. The dynamics of these concepts are however more commonly explored within the workings of complex or dynamic physical systems. Yet, the broad applicability of the underlying ideas offers the possibility of identifying similar concepts in biological systems and by extension, the field of entrepreneurial cognition and behavior. Thus, the paper adopts an interdisciplinary approach and employs retroductive reasoning in the assemblage of relevant ideas, sought from diverse literary sources. The outcome is a conceptual framework, which presents certain propositions that offer implication for action.
\end{abstract}

KEY WORDS: Venture, Complex System, Adaptive Agents, Self Organization

\section{INTRODUCTION}

Venture emergence is often expressed as complex, heterogeneous, multiform and multidimensional phenomenon (Cunningham \& Lischeron, 1991; Bruyat \& Julian, 2001; Gartner, 1995). Any inquiry into the workings of venture emergence would mean delving into the phenomenon of entrepreneurship, and this tends to precede in various directions, with different theoretical stance, multifarious units of analysis and diverse methodological perspectives. Consequently, a number of paradigms have emerged as dominant theoretical constructs in entrepreneurship studies. In relation to this, Aloulou, (2017), specifies four paradigmatic approaches that are frequently employed, in the study of entrepreneurship. These include viewing the phenomenon as the discovering and exploitation of profitable opportunities; a dialogic between individual and new venture creation; as innovation or creative destruction; and as organizational or venture emergence. While recognizing all of these as representing the various aspects of entrepreneurship phenomena, the idea of venture emergence is nevertheless nested in complexity sciences.

Complexity science as a field of study embodies the collection of ideas, principles and influences, from other bodies of knowledge. It encompasses therefore, more than one theoretical stance and is highly interdisciplinary, seeking answers to some fundamental questions about living, adaptable and changeable systems. It is in fact this interdisciplinary feature, particularly in relation to such disciplines associated with cybernetics, chaos theory, and complex adaptive systems (Ramalingam, Harry, Toussaint\&John, 2008), that complexity science stand amiable to the field of entrepreneurship. Thus, entrepreneurship and complexity science are linked in a number of important ways, andas Lichtenstein, (2011) rightly observes, studies of entrepreneurship and complexity science are both focused on innovation, novelty and emergence.

Therefore, both fields explore interactions as well as emergent phenomenon at multiple levels of analysis, and often highlights the importance of non-linear and unpredictable processes that generate emergent order in dynamic systems. McKelvey, (2004), emphasized, that complexity sciences study non-linear outcomes resulting from rapid phase transitions, which are caused by adaptive tensions and co-evolutionary processes, often set in motion by seemingly inconsequential instigating events. It is within this context, and particularly with respect to order creation that entrepreneurial activity is thus considered a function of control parameter, adaptive tension and phase transitions, which motivate agents' self- organization (McKelvey, 2004).

In this sense, the emergence of an order in a system is considered more or less a co-evolutionary process arising from interaction between heterogeneous agents in the system, characterized by constant change and mutual dependence between agents, (Holland,1997, Lichtenstein, 2011), as well as sensitivity to initial conditions (Gleick, 1987). It is based on these considerations, that the concept of phase transition, especially as it relates to self-organization of agents towards emergence, that the concept leans towards a psychological view of entrepreneurship. 


\section{Phase Transitions and Bifurcation Points in the Initiation Dynamics of Venture Emergence: A Conceptual Framework}

Viewing phase transitions through a psychological lens and within the context of complexity sciences and entrepreneurship studies, this paper offers a perspective that stresses the significance of bifurcation points in entrepreneurial process. The paper thus builds upon the foundation of relevant literature in the fields of complexity sciences, dynamic psychology as well as the cognitive and behavioral perspectives of entrepreneurship. It explores features of complex adaptive agents through the lens of entrepreneurial action and venture emergence. The essence is to suggest actionable propositions, that offer possibilities for increasing the chances of securing success of emergent ventures especially by nascent entrepreneurs.

To proceed thus, the paper is structured into four sections. Following this introduction is section two, in which are clarified, the concepts guiding the exploration. In section three, a synthesis of these concepts is attempted, which is accompanied with a deduced set of propositions with implication, and then followed by a conclusion in the final section.

\section{CONCEPTUAL CLARIFICATION OF KEY TERMS}

For the prevailing purpose, the paper discusses the following key terms with a view to situating same, within the context of intellectual argument building. At the end, a meaningful point of convergence is arrived at, which is used in explicating the conceptual synthesis?

\subsection{Complex Adaptive System and Adaptive Agency of the Entrepreneur}

Complex systems are made of adaptive agents and are distinguished by the term complex adaptive systems, (Ramilgam et al, 2008). A complex adaptive system is a system which persists in spite of changes in the diverse individual components of which it is comprised. The interactions between those components are responsible for the persistence of the system and the system itself engages in adaptation or learning (Holland, 1997). Complex systems are thus said to be adaptive or evolving, when individual adaptive agents respond to forces in their environments via feedback. Regardless of size and nature however, adaptive agents share certain characteristics, even though they react to the environment differently (Eidelson, 1997).

In this sense, some of the characteristics of complex adaptive agents are reminiscent of attributes akin to those possessed by entrepreneurs, and this offers basis for establishing a connection between the nature of a complex adaptive agent and that of an entrepreneur. For instance, Harvey (2001) views adaptive agents as being goal directed; and always attempting to exert control over their environment in order to achieve these goals. This view, further suggests that agents may have goals that can take on diverse forms, including desired local states; desired end goals; rewards to be maximized; and internal needs or motivations that ought to be kept within desired bounds.

Impliedly, Complex adaptive agents can sense the environment and respond through physical or other behaviors or actions. They might as well have internal information processing and decision-making capabilities, enabling them to compare the environmental inputs and their own behavioral outputs with their goals. This means they anticipate future states and possibilities, based on internalized models of change and this anticipatory ability often significantly alters the aggregate behavior of the system of which an agent is part, (Harvey, 2001).

Looking at these characteristics, it would seem as though the entrepreneur is just another term for a complex adaptive agent. Yet, these characteristics are possessed by all living things considered to be essentially complex and adaptive. Of these characteristics however, those associated with the concepts of goal and motivation, stand to be of particular interest to the current discourse. This is because the idea that adaptive agents are goal directed and attempting to always exert influence over their environment, seems distinctively entrepreneurial, considering the fact that this is what most entrepreneurs actually do. But, while doing this, adaptive agents just like entrepreneurs, anticipate desired future states and possibilities, and this could mean being prone to a motivation that is understandably tied to a given passion, thus serving to act as a driving force behind an entrepreneurial intent or endeavour.

In view of this conceptual similarity, an entrepreneur could be considered more or less a complex adaptive agent. If this be the case, then one could as well speak of the entrepreneur's adaptive agency as means by which the goal of any entrepreneurial pursuit could be attained. Such a means is however tied to a process and from view point of entrepreneurship, such a process would constitute among other things the dynamics of learning and adaptation. But, learning is also associated with meaning or sense making, in a way that bears semblance to feature of an 'order parameter' in complex adaptive system, just as adaptation could be said to bear semblance to yet another feature, akin to self-organization in such systems. Hence, to gain understanding of the means by which entrepreneurs attain their goals from the perspective of complexity, there is need to further explore the concepts of order parameter and self-organization and examine their interaction within the appropriate context.

\subsection{Order Parameter and Self-Organization}

Self-organization constitutes one of the features of a complex adaptive system. It is a tendency that naturally progresses from chaotic, disorganized, undifferentiated independent states, to organized, highly differentiated, and highly inter-dependent states (Farmer, 1995). Central to this phenomenon is the interplay between constancy and change as the system maintains its essential identity while undergoing self-induced, nonlinear transformations. This transformation occurs owing to interactions among a system's individual components that produce macroscopic properties referred to as 'order parameters'. In this sense an order parameter represents the principle upon which self-organization is predicated. But, if self-organization involves undergoing transformation and order 


\section{Phase Transitions and Bifurcation Points in the Initiation Dynamics of Venture Emergence: A Conceptual Framework}

parameter is that, which influences such transformation, then learning could be likened to an order parameter just as adaptation could be seen to represent a form of transformation that results from the activity of order parameter or the learning process.

Thus, the concept of order parameters is in this sense descriptive of the important features of a variety of complex adaptive systems in the behavioral and social sciences and has been used accordingly in a number of ways. For instance, in human cognition, Stadler and Kruse (1995) have identified 'meaning' as an order parameter for high-level brain processes that induces learning, which serves as the organizational basis for the memory of complex verbal chains. Likewise, within the economic realm, a business firm's profits can act as an order parameter for the company's diverse activities that involves learning from experience, while in the larger society, the difference in the number of citizens supporting two opposing solutions can operate as an order parameter for the community's response to an important problem predicated on learning from past experience (Wishcert\& Wunderlin, 1993).

Viewed in this sense the concepts of self-organization and order parameter and their functionality in the dynamics of complex adaptive systems, stand analogous to the function of entrepreneurial learning and adaptation in the complex process of venture emergence. But to fully understand this functionality, it is important to introduce two other important concepts of the complexity approach, These are intrinsic dynamics and positive feedback.

\subsection{Intrinsic Dynamics and Positive feedback}

Self-organization process does not inevitably lead the complex adaptive systems to a single fixed or static state, since such systems are known to often exhibit internally generated fluctuations beneath their macroscopic stability. These persistent internal fluctuations intermittently produces bursts of momentary instability and volatility before relaxing to equilibrium once again, and from view point of complexity, this results from what is generally being referred to as intrinsic dynamics, (Eidelson,19997). Such intrinsic dynamics manifests itself even in large multiagent systems such as human society. For instance, in the efforts to optimize their individual outcome, adaptive agentsor entrepreneurs, are capable of switching strategies as the entire societal system evolves. It could be maintained therefore, that even when resource use, reaches a stable equilibrium state for the system as a whole, the agents would continue to switch strategies in pursuit of greater individual returns, (Youssefmir\& Huberman, 1995),

This tendency is however influenced by Positive feedback, and the dynamics of the positive feedback cycle are self-reinforcing, and tends to potentially amplify the impact of a small change or adjustment, such as when successful learning drives an individual, organization, or society to a stable but suboptimal solution, (Eidelson, 1997). This means that the survival or success of a given complex adaptive system, is often dependent on its capacity to effectively modify goal-oriented behavior in response to a changing situation or environment.

Furthermore, these adaptations are not necessarily passive, in many cases the system responds actively with behaviours designed to influence and perhaps even control the environment (Hubler\& Pines, 1994). Which means a complex adaptive system is capable of generating its own patterned evolution and yet exhibit abrupt, nonlinear, and often dramatic transformations from one reference state to a qualitatively different one, especially when sufficiently perturbed by internal or extremal forces. From the dynamical systems perspective, this discontinuity is referred to as phase transition( Prigogine \&Stengers, 1984), and the driving force which pushes such systems towards phase transition and resultant bifurcation points is often known as 'Control Parameter', (Nowak \&Lewenstein, 1994). Thus, the concepts of phase transition, control parameter and bifurcation points constitutes a trio that animates the activities of a complex adaptive system and these needs to be clarified further.

\subsection{Phase transition, Control Parameter and Bifurcation Points}

Phase transition represents a crucial characteristic of an organism's perceptual dynamics. Thus, like other signatures of complex dynamical systems that show up in human data, exhibiting a phase transition is also a paramount signature in human cognition, where initial increases in some parameter have little or no effect in the system behaviour. But, at some point, a threshold is nevertheless crossed and tiny increase in that same parameter suddenly induces massive changes in system behaviour ( Spivey, Anderson \& Dale, 2008). Such a parameter is often known as the Control Parameter. It is important to note thatwhen change in a given Control Parameter approaches a certain junction, the system becomes increasingly unstable and begins to display critical fluctuations (Haken, 1983). At the critical value itself, the system reorganizes and assumes a significantly different form at one juncture, usually referred to as bifurcation point. Bifurcation point thus represents a threshold which abruptly transports a complex adaptive system to a qualitatively different and reorganized state. In other words, it represents random perturbation or intentional influence that determines which particular chosen course, leads to renewed stability (Eidelson, 1997). Thus, it is at these critical points of bifurcation that changes in patterns of behaviour become readily distinguished.

\section{CONCEPTUAL SYNTHESIS: THE KEY ASSUMPTIONS}

Based on the foregoing, it is clear that relevant to comprehending the notion of Bifurcation Points are the functionalities inherent in the concepts of order parameter; intrinsic dynamics; self-organization; positive feedback and control parameter. These stand to offer the best opportunity for identifying the dimensions, which are in all likelihood, relevant to a system's attitude. This is important also, considering the fact thatattitude provides the state of readiness for exhibiting a given behavior (Weber, 2013). Thus, the 


\section{Phase Transitions and Bifurcation Points in the Initiation Dynamics of Venture Emergence: A Conceptual Framework}

tendency for an entrepreneur to exhibit any form of entrepreneurial behavior takes effect, subsequent to developing an entrepreneurial attitude.

It is most important however, to think of entrepreneurial attitude, in terms of a given state, characterized by continuous flux. This in turn owes to the activity of intrinsic dynamics, which in this context, stands to continually propel the entrepreneurs' attitudinal tendencies towards initiating appropriate responses to contingencies, owing to continuous learning and thereby aiding the attainment of self-organization or adaptation. Hence, it is reasonable to assume, that due to this capacity for self-organization or adaptation, which becomes reinforced owing to positive feedback, entrepreneurs are most likely to develop varying attitudinal mindsets, across phases of a developmental trajectory, while passing through entrepreneurial process and seeking the exploitation of opportunities.

It is further assumed that the outcome of variation in the attitudinal mindset of entrepreneurs as they exercise efforts towards venture creation, ought to share semblance with the characteristic nature of phase transitions as manifested in other dynamic systems. If this be the case, then it remains plausible to also recognize the effect of certain defining moments, in which an entrepreneur stands more likely, to tend towards altering his behavior or acting in a qualitatively different direction, due to the consequent increase in learning and adaptation, leading to evolving phase transitions.

Thus, in as much as defining moment in human experience induces a change in behavior, then when conceived within the frame of reference of phase transitions and complex adaptive agency, such an idea would stand analogous to the concept of bifurcation points particularly in the process of venture emergence. In accordance with this logic therefore, the following synthesis aims at developing a conceptual framework that would provide a set of propositions, which borders around the initiation dynamics of the process.

\subsection{The Initiation Dynamics}

The initiation dynamics of entrepreneurial process, consists of a transformative movement along the trajectory that represents changes in the attitudinal mindset of the entrepreneur. This further translates into a specific attitudinal preference for a given behavioral response that befits prevalent circumstances, but with a dynamic recurrence that perpetuates to reveal new set of entrepreneurial possibilities as the circumstances change overtime. Thus, starting with the influence of prior experience to denote "phase one" of the initiatory process, subsequent transitions are anticipated and delineated in terms of movement through phases two, three and four to describe occurrences and identify the bifurcation points along the developmental trajectory of the process. The following description assumes an interdisciplinary approach and is meant to represents a synthesis of ideas gathered from diverse but related sources.

\subsubsection{Phase One: Pre-launch}

This phase represents what happens when an entrepreneur operates within the cognitive frame of prior experience. As such, it reflects the intrinsic dynamics that influences the choice of behavior, while the entrepreneur exerts effort towards opportunity discovery. The content of an attitude is here considered to be determined by the cognitive and affective mental states (Webber, 2013). Thus, the conditioning effect, which derives from prior experience, is here envisaged to have direct bearing on cognition and affect of the person involved.

As such, prior experience remains useful, since it reinforces the entrepreneur's tendency towards discovering or identifying opportunities. Thus, the content of entrepreneurial "intentional attitude", which represents mental state directed towards opportunity seeking, would under the influence of prior experience be oriented, more in the direction of opportunity discovery.

Furthermore, the entrepreneur's cognitive and affective elements that tends to influence the pursuit of interest in this regard, would involve utilizing perception to ascertain that which appears desirable, or in other words develop perceived desirability for a particular outcome. This cannot be independent of motivation however, which could be considered to be driven by utility anticipation, relative to pursuit of a given entrepreneurial event.

Thus, perception and motivation are within this context, rendered as important mental states, which interact meaningfully with an entrepreneur's knowledge and disposition to influence the choice of appropriate behavioral response. Under the imprint of prior experience therefore, and through the interpretation of what obtains from the interaction of stimuli induced by externalities and what prevails as the constituent mental states of the entrepreneur, an attitudinal mindset that defines the behavioral responses and actions taken by the entrepreneur develops. These externalities could otherwise be termed external enablers (Davidson, 2015),thus representing a set of contingencies that are characterized by such things as changes in technology for instance, demography, regulatory framework and natural environment which are thought of by some scholars as having the capacity to trigger new venturing events (Alvarez \& Barney, 2013; Davidson, 2003; Dimov, 2011, Shane, 2012).

Thus, in what is here conceptualized as the pre-launch stage of the entrepreneurial activity, this attitudinal mindset finds expression through a behavior that tilts more in the direction of what could be considered improvisation on the part of the entrepreneur. The term improvisation implies thus, a behavior that is characterized by the simultaneous design and execution of action (Baker, Miner \& Esley, 2003). It becomes the resulting behavioral response to the initial stimuli triggered by these external enablers, and tends to inspire certain entrepreneurial actions that lead to developing idea initiatives for new venture creation.

With the saturation of these idea initiatives, new set of entrepreneurial stimuli, in form of opportunity confidence (Davidsson, 2015) develops, and at such a point when this happens, the entrepreneur would experience the situation as a defining moment, which 


\section{Phase Transitions and Bifurcation Points in the Initiation Dynamics of Venture Emergence: A Conceptual Framework}

determines all subsequent related occurrences. It is at this juncture, that the entrepreneur is perhaps instigated enough to behave and act in a qualitatively different manner.

Thus, this experiencing of a defining moment, which is here presumed to be induced by a feeling of opportunity confidence, tends to provide a kind of positive feedback, that encourages the yielding of new ideas, thus becoming the first bifurcation point along the trajectory. The possibilities suggested by these dynamics are here subsumed in the following propositions:

Proposition 1: The pre-launch phase of the entrepreneurial process and the attitudinal mindset that characterize it, are influenced by the imprinting effect of prior experience. This in turn, has the effect of conditioning knowledge, disposition and the capacity for choice, such that the stimulus derivable from external enablers, which influences the entrepreneur, is interpreted in light of the need for opportunity discovery.

Proposition 2: The perceived desirability for opportunity discovery becomes operational when backed by the motivation that is driven by utility anticipation, and the behavioral response, related to improvisation is activated and manifested. This has the effect of aiding the entrepreneur to experiment with new venture idea initiatives such that his opportunity seeking and exploitation is further sustained by the emergence of opportunity confidence as new stimulus.

\subsubsection{Phase Two: Launch}

The bifurcation point of the pre-launch phase as articulated in the foregoing, marks the beginning of the dynamics which characterize the second developmental phase driven by the mental processes influenced by Reflexivity. This presupposes a shift towards a qualitatively different mode of executing around priorities. Here, the entrepreneur learns to think "outside the box" by cutting ties with the preceding effect of imprinting, due to becoming exposed to new vistas of possibilities other than the ones, which initially influence his initial value orientation.

This change in perspective enhances his reflexive capacity, and through increased level of engaged imagination, the entrepreneur expectantly becomes bent on creating opportunities rather than the initial determination to discover them. In this sense, reflexivity is taken to represent the capacity for individuals to interpret current actions and to understand what they are doing while they are doing it, (Giddens, 1988). This makes it possible for recently activated intrinsic dynamics or cognitive representations to exert potent influence on the processing of encountered information. In other words, the reflexive capacity of an entrepreneur, impacts on his recent experiences in ways that enable such experiences to routinely influence his subsequent perception, judgment and entrepreneurial behavior. This development would involve developing new sets of interaction with other constituent mental states of perception, and the motivation that is likely to emerge due to change in perspective. This would include perceived feasibility for earning the outcome of creative effort, and the motivation, which stands positively driven by assumed reality.

The resulting impact of this interaction on the entrepreneur's knowledge base and personal disposition would in turn influence the entrepreneur's choice for appropriate behavioral response to the new stimulus. The behavioral response which appears most suitable to this situation is effectuation, the starting point of which is not the goal to be achieved, but the means of achieving it, (Frese\&Gielnik, 2014). Effectuation thus enables the entrepreneur, to make do with what comes his way, and learn to transform both positive and negative contingencies into useful components of new opportunities (Dew, Read, Sarasvathy \& Wiltbank, 2009). But, since creativity is indispensable to this process, creative efforts necessarily ensues. These creative efforts would naturally culminate into new set of experiences, which defines entrepreneurial event in new light as opposed to the prior assumption that influences initial entrepreneurial efforts. Thus, the entrepreneur gains a new level of understanding that facilitates his acquaintance with experiential reality, the attainment of which represents another defining moment for the entrepreneur, hence another bifurcation point. Consequently, previous preconception is replaced with new set of possibilities, which emerge in light of fresh experiences, leading to a qualitative change in behavior. It is in view of these possibilities that the following propositions are posed:

Proposition 3: The launch phase of the entrepreneurial process and the attitudinal mindset that characterize it, are influenced by reflexivity, which enables subjective rationalization of occurring events. This in turn has the effect of shaping knowledge, disposition and the capacity for choice, such that the stimulus derivable from the feeling of opportunity confidence, which influences the entrepreneur, becomes interpreted in light of need for opportunity creation.

Proposition 4: The perceived feasibility for opportunity creation enables the actual execution of intent based on assumed reality, which confers the motivation and manifestation of effectuation as behavioral response. This has the effect of aiding the entrepreneur to embark on creative efforts, such that his experiential reality becomes impressionable as new stimulus, thus furthering the sustainability of efforts directed towards opportunity seeking and exploitation.

\subsubsection{Phase Three: Post-Launch}

The bifurcation point of launch phase, which in the preceding is thought of as facilitating opportunity creation, paves way for developing the capacity to engage in a new kind of thinking influenced by idiosyncrasy. This is because opportunities take form as entrepreneurs define them, and unique ventures are necessarily built around idiosyncratic interpretation of ongoing experience (Sarasson, Dean and Dilland, 2006).It is important to note also, that multiple individuals do not pursue the same kind of opportunity and this points to the subjective nature of opportunity recognition. In a very real sense therefore, it is possible that the entrepreneur learns to create his or her own opportunity sets (Buchanan \& Pierror, 1980). 


\section{Phase Transitions and Bifurcation Points in the Initiation Dynamics of Venture Emergence: A Conceptual Framework}

Thus, opportinities could be considered to be enacted on the basis of the entrepreneur's perception, interpretation and understanding of environmental forces,(Dutta \& Crossan, 2005).Yet, the entrepreneur's ability to perceive and infer correctly, that which constitute the true driving force and the critical factors of the market environment and the real relational dynamics among the elements contained therein, would require proper apprehension of the changing environmental cues and reassesement of the situation and environment, (Gaglio \& Katz, 2001).

Each entrepreneur therefore confronts a unique situation that confers the possibility of gaining oportunity ownership. But, for this to be attained, gradual transformation necessarily ensues, leading to the development of self efficacy. Apart frombeing a derivative of this process, self efficacy as a product of perception is here used to denote the entrepreneur's belief in his ability to perform or effectuate a given outcome (Bandura, 1994). This comes however, subsequent to gaining a sense of creative awareness, which on the part of the entrepreneur develops overtime andis manifested with increased level of experience, whilehis pursuit of entrepreneurial success perpetuates and his focusremains sustained.

Suchmanifestation is however accompanied by a realistic confrontation with challenging entrepreneurial events, which do not comform with the entrepreneur's initial expectations. Yet, the combined effect of the motivation that results from his sense of creative awareness and perception of his self efficacy, would eventually lead tothe choice of bricolageas befitting behavioral response to such a stimulus. This is because bricolage is characterized by a behaviour that manifests in the having to "make do" of available means, by applying combination of the resources at hand to new entrepreneurial problems and opportunities (Baker \& Nelson, 2005). Thus, making possible, the persistant pursuit of entrepreneurial possibilities. With such persistance, efficaciouse actions necessarily ensues.

As such, the resulting outcome of efficacious entrepreneurial actions would have a high tendency of producing positive feedback, which invariably leads to the development of pleasant feeling or emotionrefered to as 'positive affect'.Experiencing positive affect, is associated with the strenghtening of individual cognitive capacities,thereby aiding the individuals to acquire such intellectual and psychological resources, which contribute to their performances on many cognitive tasks (Baron, Hmieleski \& Henry, 2012).

However, the outcome of any efficacious action resulting from such sense of elation could be a defining moment, or better still be considered a bifurcation point, the reaching of which enable the perpetuation and advancement of the process along the trajectory, but with aqualitatively different set of modalities. In view of this, the following propositions are posed:

Proposition 5: The post launch phase of the entrepreneurial process and the attitudinal mindset that characterized it are influenced by idiosyncracy, which stimulates the unique interpretation of ongoing experience. This inturn has the effect of shaping knowledge, disposition and the capacity for choice, such that the stimulus inspired by experiential reality, renders the the entrepreneur capable of assuming opportunity ownership.

Proposition 6: The perceived self-efficacy that results from the motivation of increased sense of creative awareness, enables the activation and manifestation of bricolage as behavioral response. This has the effect of aiding the entrepreneur to embark on efficacious action, such that opportunity seeking and exploitation remain sustained by the emergance of positive affect as new stimulus.

\subsubsection{PhaseFour: Sustainability}

The bifurcation point of post-launch phase induces the capacity for metacognition, which in the present context relates to the utility derivable from positive affect when it becomes externalized in terms of its enabling effect. Such that, the entrepreneur persists in his simultaneous use of both predictive and creative logic, while making entrepreneurial decisions. This dynamics presumably inspires perceived controllability, which is accompanied by the development and the use of heuristics, which is expected to become perfected overtime.

Heuristics usually refers to simplifying strategies that individuals use to manage information and reduce uncertainty in decisionmaking (Khaneman\& Tversky 1973). Thus, in the context of entrepreneurship, heuristics is a developed form of simplifying cognitive mechanisms, which entrepreneurs use in complex situations without which, many entrepreneurial actions would be paralyzed (Manimala, 1992).

It therefore represents entrepreneurs' unique knowledge structures, with which they become able to process information differently from non-entrepreneurs, (Mitchel, 1994). Furthermore, ability to make such effective decisions makes entrepreneurs capable of developing a kind of expertise, which forms a part of their personal repertoire and influence the way they think and make sense of an evolving situation (Mitchell, 1994).

Thus, it would be reasonable to assume that an entrepreneur, who operates, under the influence of positive affect, must have experienced a defining moment which would inspire the acquirement of such capability. If this were the case, then it would as well be reasonable to further suggest that the entrepreneur, would readily engage in metacognitive thinking, which is envisaged as a capacity that supports self-reflection, the enhancement of one's understanding and the control of one's own entrepreneurial cognitions, (Mitchell, Randolph \& Mitchell, 2011).

Thus metacognitive ability serves as precursor to enabling the sustainment of efforts towards developing the required kind of expertise. But gaining expertise in entrepreneurial sense and putting to it use is in itself a defining moment since it determines the quality of subsequent occurrences once gained, and this is akin to reaching a bifurcation point. When this happens, then one would 


\section{Phase Transitions and Bifurcation Points in the Initiation Dynamics of Venture Emergence: A Conceptual Framework}

expect that the entrepreneur becomes able to sustain the carrying out of effective actions in ways that facilitate the attainment of desired results. It is in view of this that the following propositions are posed:

Proposition 7: The sustainability phase of the entrepreneurial process and the attitudinal mindset that characterized it are influenced by metacognition, which confers the ability for the understanding and control of one's cognition. This in turn has the effect of shaping knowledge, disposition and the capacity for choice, such that the resultant positive affect renders the cognitive ability of the entrepreneur potent, for the effective and continuous pursuit of opportunity exploitation and exploration.

Proposition 8: The state of perceived controllability, which results from active wielding of metacognitive ability and the possibilities inspired by the active use of developed heuristics, would influence the entrepreneur's inclination to adopt behavioral pattern that unleashes his expertise. This has the effect of aiding the realization of desired results through the continuous execution of effective actions so as to secure the perpetuation of the process.

It is important to note that all the preceding propositions serve as premise, upon which the centrality of the entrepreneur as complex adaptive agent in the process of venture emergence is predicated. Allthe essential ideas embedded in the propositions are represented in figure 1:

\section{FIGURE 1 : PHASES AND BIFURCATION POINTS IN VENTURE EMERGENCE}

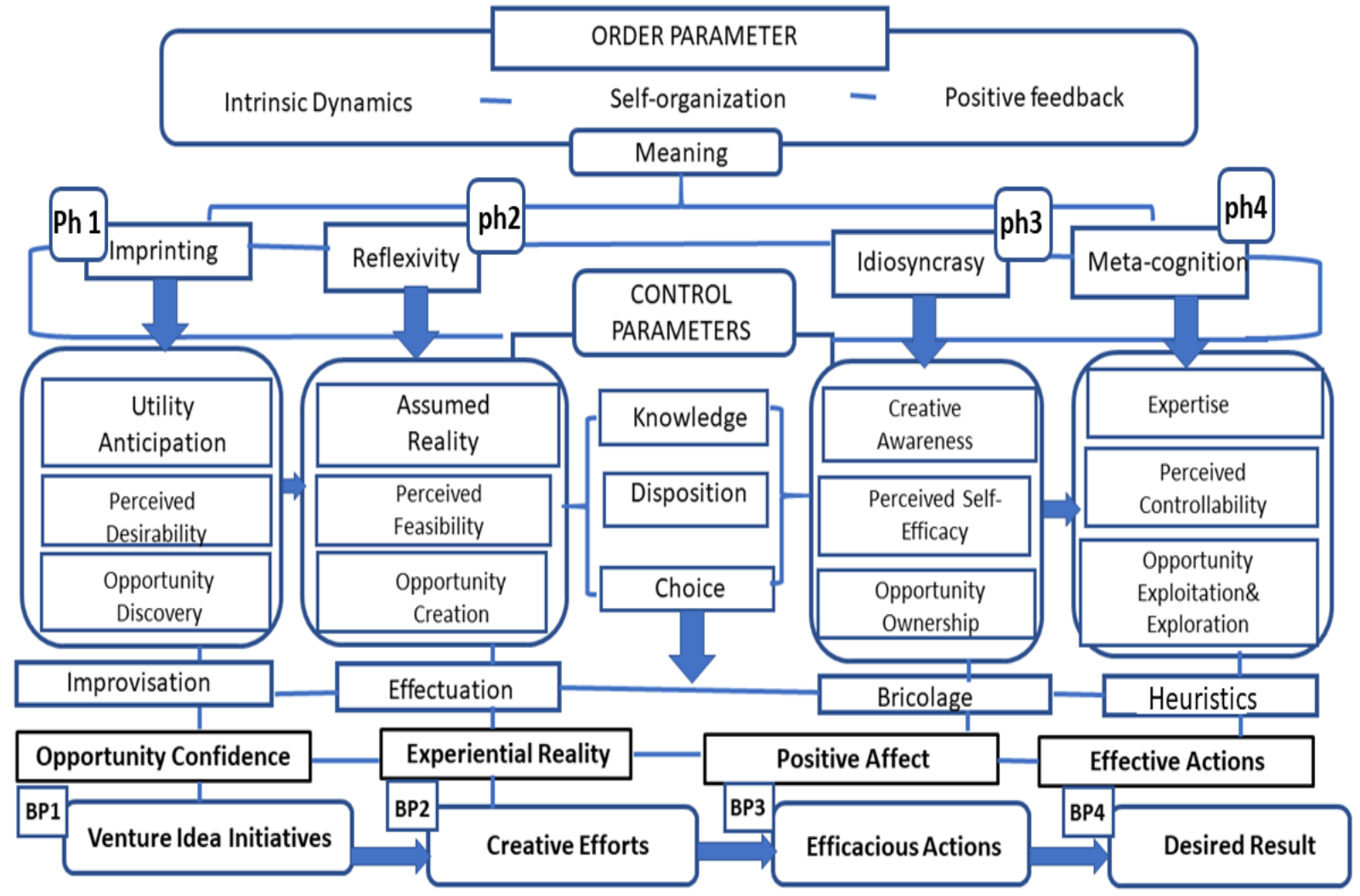

Source: The Author, 2021

\subsubsection{Implication}

The ideas articulated in the forgoing represent possibilities associated with efforts of the entrepreneur, whose agency coincides with the dynamics of a complex adaptive system, the workings of which is here presumed to remain pivotal, relative to realizing the idea of new venture creation. The implication of this, is dependent upon how the dynamics associated with the envisaged antecedents at the verge of a phase transition, or the consequences of attaining a bifurcation point, are understood and utilized, relative to channeling the efforts of nascent entrepreneurs towards realizing their set objectives.

This is because all of the antecedents and consequences that have been expressed, in terms of intrinsic dynamics, self-organization, positive feedback and their alternative connotations, have implication for action, but to the extent that any such action remains the outcome of deliberate design, the making of which takes as premise, the ideas expressed in the stipulated propositions. This is more so, if the envisaged utility of these ideas is not only appreciated but actuated, in terms of tapping into the possibilities they represent in real life context, particularly when occasioned to be applied, in such instances where the entrepreneurs are encouraged to exert efforts towards venture emergence. Yet, any such attempt would only be worth while and practicable, if the implied cognitive and 


\section{Phase Transitions and Bifurcation Points in the Initiation Dynamics of Venture Emergence: A Conceptual Framework}

behavioral patterns associated with the phase transitions and bifurcation points, are considered in the design and execution of coaching and mentoring plans, aimed at facilitating entrepreneurship within the appropriate contexts.

\section{CONCLUSIONS}

The propositions that have been advanced, echo the eidos or the personal cognitive paradigm of the entrepreneur, with which he filters information, while attempting to create 'meaning' out of prevailing circumstances in the process of initiating venture emergence. The idea of meaning, is here explored through the lens of a complexity concept, referred to as 'order parameter'. This concept is central to the present conceptualization, in that it offers the basis for the presumed manifestation of certain occurrences, which along the entrepreneurial path, finds expression in action.

Such manifestation is however considered to be dependent on the quality of 'learning' and the extent of 'adaptation', given the connection these concepts have with the idea of 'meaning' or 'sense making'. It is also deemed reasonable to equate the concepts of 'learning' and 'adaptation' with notions of 'intrinsic dynamics' and 'self-organization', owing to similarities in their functionalities.

It is equally presumed that alteration in the entrepreneur's knowledge, disposition and choice, tends to affect and be affected by learning and adaption. If this be the case, then it is reasonable to posit that any implication, which ought to manifest in action, should be sought in the meaning the entrepreneur ascribes to ongoing events. But, variation in meaning is often expected to manifest whenever there is change in circumstances. Therefore, any experience the entrepreneur gains as a result of change, would necessarily impact his knowledge and disposition in ways that influence the making of new choices, and this is analogous to the functionality of a 'control parameter'. In this sense, a control parameter determines the change in movement along the entrepreneur's developmental trajectory and across phases of his venture creation process, such that this appears reminiscent of experiencing a 'defining moment' at critical stages of development.

Hence, knowledge, disposition and choice are here equated with control parameter, in that the impact these exert over the manifestation of certain cognitive and behavioral tendencies, spread across, in respect of both the antecedents and consequences of initiating an entrepreneurial action. In view of these, the paper posits that the envisaged possibilities associated with both the antecedents and consequences of treading the entrepreneurial path in terms of both phase transitions and bifurcation points, stands justifiable. This is while acknowledging the fact that this perspective is largely speculative and yet to be expressed same way, in any entrepreneurial context. Thus, it is shrouded with many ambiguities, which would require further research to be clarified and validated.

\section{REFERENCES}

1) Aloulou, W. (1991). Investigating Entrepreneurial Intentions and Behaviour of Saudi Distance Business Learners: Main Antecedents and Mediators. jornal of International Business and Entrepreneurial Development, 231-257.

2) Alvarez, S., \& Barney, J. (2012). Epistimology, Opportunities and Entrepreneurship: Comments on Venkatareman et al, 2021 and Shane 2012. Academy of Management Review, 154-157.

3) Baker, T., \& Nelson, R. (2005). Creating Something from noting:Construction through Entrepreneurial Bricolage. Administrative Year Quarterly, 329-366.

4) Baker, T., Miner, A., \& D, E. (2003). Improvising Firms: Bricolage Account Giving and Improvisational Competencies in the Founding Process. Research Policy, 255-276.

5) Bandura, A. (1994). Exercise of Personal and Collective Efficacy in Changing Society. In A. Bandura, Self Efficacy in Changing Society (pp. 1-45). Newyork: Cambridge University Press.

6) Baron, R., H, Hmieleski, k., \& Henry, R. (2012). Entrepreneurial Dispositional positive Affect:The Potential Benefit and Potential Cost of Being Up. Journal of Business Venturing, 310-324.

7) Bruyat, C., \& Julien, P. (2000). Defining the Field of Entrepreneurship. Journal of Business Venturing, 165-180.

8) Buchanan, J., \& Pierro, A. (2005). Cognition,Choice and Entrepreneurship. Southern Economic Journal, 425-499.

9) Cunningham, J., \& Lischeron, J. (1991). Defining Entrepreneurship. Journal of Small Business Management, 45-61.

10) Davidson, P. (2003). The Domain of Entrepreneurship Research: Some Suggestions. Advances in Entrepreneurship, Firm Emergence and Growth, 315-372.

11) Davidsson, P. (2015). Entrepreneurial opportunities and the Entrepreneurship Nexus: A Reconceptualization. Journal of Business venturing, 674-695.

12) Dew, N., Read, S., Sarasvasty, S., \& Wiltbank, R. (2009). Effectual versus Predictive Logic in Entrepreneurial decision making. Journal of business venturing, 287-309.

13) Dimov, D. (2011). Grappling with the unbearable of Entrepreneurial Opportunities. Entrepreneurship theory and Practice, 57-81.

14) Dutta, D., \& Crossan, M. (2005). The Nature Entrepreneurial Opportunities:Understanding the Process Using Organizational learning Practice. Entrepreneurship Theory and Practice, 693-701. 
Phase Transitions and Bifurcation Points in the Initiation Dynamics of Venture Emergence: A Conceptual Framework

15) Eidelson, J. (1997). Complex Adaptive Systems in Behavioral and Social Sciences. Review of General Psychology, $42-71$.

16) Farmer, J. (1995). The Second Law of organization. Newyork: Simun and Schuster.

17) Frese, M., \& Gielnik, M. (2014). The Psycology of Entrepreneurship. Annual Review of Organizational Psychology and Organizational Behaviour, 413-438.

18) Gaglio, C., \& Katz, J. (2001). The Psychological Basis of Opportunity Identification. Small Business Economics, $95-111$.

19) Giddens, A. (1988). Central Problem in Social Theory. London: Macmillan.

20) Gleick, J. (1987). Chaos. Newyork: Pengum Books.

21) Harvey, D. (2001). Chaos and Complexity:Their Bearing on Social Policy Research. Social Issue, 1-2.

22) Holland, J. (1997). Emergence . Philosophica, 11-40.

23) Lichtenstein, B. (2011). Levels and Degrees of Emergence International Journal of Complexity in Leadership and Management, 252-74.

24) Manimala, M. (1992). Entrepreneurial Heuristics: A Comparison between high PI and Low PI Ventures. Journal of Business Venturing, 477-504.

25) McKelvy, B. (2004). Towards a Complexity Science of Entrepreneurship. Journal of Business Management, $313-341$.

26) Mitchell. (1994). Stakeholder theory and Liability of Newness in New Ventures. In W. S.A, International Association for Business and Society Proceedings (pp. 345-350). Hilton Head.

27) Mitchell, R., Randolph-Seng, B., \& Mitchell, J. (2011). Socially Situated Cognition: Imagine new Opportunities for Entrepreneurial Research. Academy for Management Review, 774-776.

28) Ramalingan, B., Harry, J., Toussaint, R., \& John, Y. (2008).. London: Overse as Development Institute.

29) Shane, S. (2012). Reflections on the 2010 AMR Award: Delivering on the promise of Entrepreneurship as a field of research. Academy of Management Review, 2010, 10-12.

30) Stadler, M., \& P, K. (1995). The Function of Meaning in Cognitive Order Formation. In P. Kruise, \& M. Stadler, Ambiguity in Mind and Nature: Multistable Cognitive Phenomenon ( 5-21). Berlin,Germany: Springer-Verlay.

31) Tversky, A., \& Kahneman, D. (1973). Heuristic for Measuring Frequency and Probability. Cognitive Psychology, $207-232$.

32) Weber, J. (2013). Character,Attitude, and Disposition. Journal of Philosophy, 12-28. 